\title{
Water Consumption Pattern in the Traditional Villas of Abu Dhabi
}

\author{
$\underline{\text { R. K. Chowdhury }}^{\text {a,b }}$ and M. A. Rajput ${ }^{a}$ \\ ${ }^{a}$ Department of Civil and Environmental Engineering, United Arab Emirates University, Al Ain, UAE \\ ${ }^{b}$ Centre for Water Management and Reuse, University of South Australia, Mawson Lakes, South Australia \\ Email: rezaulkabir@uaeu.ac.ae
}

\begin{abstract}
The municipal water consumption in the Emirate of Abu Dhabi, United Arab Emirates, is extremely high (565 to 920 litre per capita per day (lpcd)), despite of their limited water resources. The residential activities account for about $52 \%$ of their expensive desalinated water. In 2013 , the total available desalinated water in the Abu Dhabi was about 244,666 million imperial gallons. This high residential water consumption is driven by their high indoor and outdoor water end uses. It was informed by the water authorities that the residential water consumption rates in the Abu Dhabi are particularly high in the traditional villa type detached houses. This study investigated the pattern of water consumptions in medium sized villas and identified the factors affecting their water consumption. The water meter reading data for a consecutive 12 month period were collected from 100 villas located in a residential compound in Abu Dhabi. All villas are uniform in their plot $\left(2050 \mathrm{~m}^{2}\right)$ and building $\left(750 \mathrm{~m}^{2}\right)$ sizes. The villas are connected to the water distribution system by a service connection pipe (Medium Density Polyethylene) of diameter $20 \mathrm{~mm}$, except three villas that have two service connection pipes. In order to verify the collected meter reading data from individual villas, the district area meter (DAM) reading was also collected for the same period. It was found that the supplied water (DAM reading) was approximately $5 \%$ more than the accumulated water consumption in all villas. This additional water was used for network flushing, fire demand and lines losses. The average monthly sewer flow (wastewater volume) from all villas were also collected. After collection of the number of people information on villas, it was found that the average per capita water consumption rate is more than $2500 \mathrm{lpcd}$. The summer (May -August) consumption was found about 5\% more than that of other months. The average indoor water consumption rate was estimated approximately $350 \mathrm{lpcd}$. The regression analysis confirmed that water consumption in the villas is not significantly dependent on the number of people live in villas, which is attributable to the fact that about $85 \%$ of water are used for outdoor activities (plantation, car washing, etc.). Finally, it was recommended to reduce the outdoor water consumption by introducing alternative water sources such as the treated sewage effluent and the treated greywater.
\end{abstract}

Keywords: $\quad$ Water demand, traditional villa, indoor water use, outdoor water use 


\section{INTRODUCTION}

The United Arab Emirates (UAE) is located in the extreme arid zone and most parts of its landscape are desert, where water is a precious and a scarce resource. The Emirate of Abu Dhabi, which is about $80 \%$ of the UAE, is located in the southern part of the Arabian Gulf and its territory area is about $67,340 \mathrm{~km}^{2}$ having a population of about 1.3 million (based on 2006 census). Despite a water scarce region, the water consumption rate in the Abu Dhabi is one of the highest in the world. The municipal water consumption rate in 2008 was between 565 and 920 lpcd (litre per capita per day), as compared to the developed countries' average range of between 160 and 220 lpcd (EAD, 2014). The most obvious reason behind this huge difference is attributable to their subsidized tariff structures and socio-cultural practices.

The Abu Dhabi receives about $65 \%$ of its total water from the conventional source of groundwater, and about $31 \%$ from non-traditional or non-conventional sources of desalination plants. This is because conventional water resources are unable to meet the demand for fresh water and now desalination of sea water is the main source of municipal water in the Abu Dhabi. The other $4 \%$ of the water comes from another nonconventional source of treated sewage effluent (TSE) (EAD, 2014).

In 2012, the agriculture, forestry and public parks sectors used about $70.7 \%$ of the total water in the Abu Dhabi, whereas $16.1 \%$ was used by domestic, $8.2 \%$ by government departments, $4.3 \%$ by commercial and $0.5 \%$ by industrial consumers (EAD, 2014). The agriculture and forestry sector is the only sector that utilized about $5.3 \%$ of recycled water and the remaining $94.7 \%$ was supplied from the groundwater resource during the year 2010. Other sectors (domestic, commercial and industrial) are still not using the recycled water and they depend on expensive desalinated water (http://www.scad.ae).

The available groundwater resources in the Abu Dhabi are estimated to be $640 \mathrm{~km}^{3}$ and less than $3 \%$ of these are freshwater. The groundwater recharge rate is less than $4 \%$ of its total annual water consumption (EAD, $2008 \mathrm{~b}$ ). The total groundwater reserve declined from $29694 \mathrm{Mm}^{3}$ (million cubic metre) to $26269 \mathrm{Mm}^{3}$ from the pre-development period to the year 2005 (EAD, 2008b). It was reported that if the current groundwater extraction rate continues, both fresh and brackish reserves will be depleted within 50 years, because the water table drops approximately 5 meters a year in the Abu Dhabi (EAD, 2014). The declination of groundwater table causes numerous impacts on the environment, including the shutdown of some wells due to deteriorating water quality and dryness. This creates a huge gap between the available groundwater resource and their increased demand for the agriculture and forestry sector.

The climate of the UAE is bi-seasonal Mediterranean type with high temperature and low rainfall. The summer (May to October) is very warm and during the day time temperatures normally exceed $40^{\circ} \mathrm{C}$. Occasional rainfall in the UAE occurs during winter (November to April) with an average rainfall of less than $100 \mathrm{~mm} /$ year (EAD, 2008b).

It is projected that the population of $\mathrm{Abu}$ Dhabi will be more than three millions, about five millions and more than eight millions by the end of 2030 for the growth rate of low (3.7\%), medium (5.8\%) and high (7.9\%), respectively (EAD, 2008b).

Consequently, the municipal water consumption in Abu Dhabi is increasing due to population growth, urbanization and rapid expansion of economic activities. Therefore, it is necessary to find alternative water sources and to conserve the existing water resources to meet the increasing water demand and to reduce the pressure of developing more infrastructures.

The water demand in the Abu Dhabi is expected to increase more than $30 \%$ by 2030 (EAD, 2014). The Abu Dhabi Water and Electricity Company (ADWEC) forecasted several years' water demand based on the current water consumption rate and estimated population growth. Table 1 shows the
Table 1: Projected water demand in $\mathrm{MG} /$ day in the $\mathrm{Abu}$ Dhabi Emirate (EAD, 2008b) (MG/day = Million imperial gallon per day)

\begin{tabular}{|c|c|c|c|c|}
\hline Year & $\begin{array}{c}\text { Available } \\
\text { water } \\
\text { capacity }\end{array}$ & $\begin{array}{c}\text { Water } \\
\text { demand }\end{array}$ & $\begin{array}{c}\text { Required } \\
\text { water } \\
\text { capacity }\end{array}$ & $\begin{array}{c}\text { Water } \\
\text { deficit }\end{array}$ \\
\hline 2016 & 830 & 960 & 1,007 & -177 \\
\hline 2017 & 830 & 987 & 1,030 & -200 \\
\hline 2018 & 827 & 1,013 & 1,066 & -239 \\
\hline 2019 & 826 & 1,039 & 1,090 & -264 \\
\hline 2020 & 825 & 1,065 & 1,113 & -288 \\
\hline 2021 & 830 & 1091 & 1136 & -261 \\
\hline 2022 & 850 & 1117 & 1159 & -267 \\
\hline 2023 & 850 & 1143 & 1182 & -293 \\
\hline 2024 & 850 & 1169 & 1205 & -319 \\
\hline 2025 & 850 & 1195 & 1228 & -345 \\
\hline 2026 & 850 & 1221 & 1251 & -371 \\
\hline 2027 & 850 & 1247 & 1274 & -397 \\
\hline 2028 & 850 & 1273 & 1297 & -423 \\
\hline 2029 & 850 & 1299 & 1320 & -449 \\
\hline 2030 & 850 & 1325 & 1343 & -475 \\
\hline
\end{tabular}


forecasted water demand in the Abu Dhabi and the projected water deficit in the region (EAD, 2008b). The projected water demand shows that there will be significant growth in water demand during the period from 2016 to 2030. If new water resources will not be developed, there will be about $475 \mathrm{MG}$ /day of water deficit by 2030 , which is more than $60 \%$ of the current water consumption. This prediction forces the authorities rely on the non-conventional water resources, such as desalination and treated sewage effluent, as well as to adopt mechanisms for water demand reduction. Therefore, a comprehensive, integrated water management plan is required in order to diversify water sources.

Over exploitation and decrease of groundwater resources, unreliable surface water and widened water supply and demand gap stressed the UAE to become the second largest desalinated water producer in the world. The desalinated water is not only an expensive source, but it is also an unsustainable solution to overcome the increasing water consumption. The desalination plants require huge energy and generate over 30 million tones of greenhouse gases (GHGs) emission $\left(\mathrm{CO}_{2}\right.$ equivalent) per year, which was $31 \%$ of the total GHG emissions in 2010 produced by power and water sector in the Abu Dhabi (EAD, 2014). In addition, desalination process is one of the major sources of marine pollution because they discharge the heated brine water into the sea (Arabian Gulf). The occurrence of these phenomena threatens the water security in the Arabian Gulf and causes numerous effects on the marine environment, aquatic life and endangered marine biodiversity (EAD, 2014)

The Regulation and Supervision Bureau (RSB) in the Abu Dhabi (www.rsb.gove.ae) reported that the

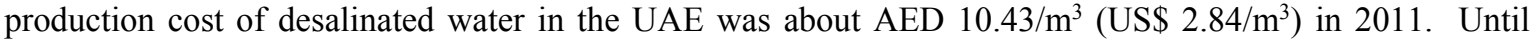
December 2014, the non-UAE nationals (expatriate) paid AED 2.20 and the UAE nationals got desalinated water free of cost. The Government subsidies in water tariff are significantly high in Abu Dhabi. From January 2015, the water tariff in villa has been increased to AED $1.7 / \mathrm{m}^{3}$ (up to $7 \mathrm{~m}^{3}$, thereafter AED $1.89 / \mathrm{m}^{3}$ ) and AED 5.95/ $\mathrm{m}^{3}$ (up to $5 \mathrm{~m}^{3}$, thereafter AED 9.9/ $\mathrm{m}^{3}$ ) for the UAE nationals and non-nationals, respectively. This is certainly a significant movement towards reducing the water consumption in the Abu Dhabi.

The efficient management and conservation of water resources is one of the top prioritized areas of the Abu Dhabi Environment Vision 2030. It emphasizes the collective responsibilities for sustainable water solutions and for the development of a water conservation strategy in order to reduce the water consumption in the Emirate. Lowering the municipal water consumption has become an essential issue for water authorities, and different measures and combination of methods are being under investigation. The reuse of wastewater/greywater is an alternative water source that can help to manage the deficiency of available water (Nitivattananon and Sa-nguanduan, 2013; Friedler and Hadari, 2006). In this study, we explored the water consumption patterns in the traditional medium size villas in the Abu Dhabi. We also explored the factors affecting the water consumption in the villas. The outcomes from the study help to identify water intervention techniques in reducing municipal water consumption.

\section{METHODOLOGY}

\subsection{Study Area}

The RSB water supply regulation (2009) estimated that the traditional villas (locally known as Shabiat) in Abu Dhabi have the highest per capita water consumption rate. Several communities were visited to select a suitable study area in the Al Ain region of Abu Dhabi. Many areas do not receive continuous (24 hours) water supply and some areas do not have smart water meters for all houses. Accordingly, a study area was selected that occupies 100 detached villas, two commercial buildings and a mosque. All the villas receive water from a single source provided by the Abu Dhabi Distribution Company (ADDC). The municipal water is supplied in the study area by the Al Ain Distribution Company (AADC). The water network consists of ductile iron pipes and all villas have a municipal water connection ( $20 \mathrm{~mm}$ service connection pipe) with a wall mounted electromagnetic water meter. The plot size of each villa is $45 \mathrm{~m} \mathrm{x} 45 \mathrm{~m}\left(2025 \mathrm{~m}^{2}\right)$. Every villa has a double storied building (townhouse) with five bedrooms. The building area is about $20 \%$ of the plot size (roughly estimated at the Google Pro) and the rest $80 \%$ area is kept open yard. The villas were constructed by the government and only the Emirati nationals are living in the study area. The open space in every villa is occupied by amenity plantations and gardening.

\subsection{Data Collection}

Two surveys were conducted in the study area. Firstly, a door to door questionnaire survey was conducted by interviewing the householders regarding their municipal water uses for different purposes, family size and their willingness for water conservation. A total of 35 villas' residents were participated in the questionnaire 
survey. Secondly, water consumption data were collected from the water meters connected to all villas. The monthly water consumption data for 100 villas was collected for a year (February 2013 to January 2014). The water meters are the properties of the AADC and the meters are enclosed and locked in a GRP wall mounted box. Prior approval was taken from the AADC to open the GRP boxes and to collect data.

The GIS drawing of the study area with water network details was obtained and the study area was divided into different blocks and the villas were coded anonymously. The divided blocks were marked as Block-A (12 villas), Block-B (12 villas), Block-C (8 villas), Block-D (10 villas), Block-E (8 villas), Block-F (12 villas), Block-G (10 villas), Block-H (12 villas), Block-J (8 villas), Block-M (8 villas) and Block-N has 3 connections (2 commercial buildings and a mosque).

The water supply source line in the study area is installed with a District Area Meter (DAM) with an electromagnetic flow meter and an RTU as a data recorder. The secondary data of monthly DAM water consumption record in the study area were obtained from the AADC in order to compare and verify the collected meter readings from individual villas. Conceptually summation of water meter readings from all buildings in the study area should be equal to the supplied water in the study area collected from the DAM's reading. However, the DAM's records indicate approximately 5\% more, which is for flushing of water network and for fire demand.

\subsection{Statistical Analyses}

The consumed water volume in the study year was divided by the population of the housing compound and the numbers of days per year to the get the per capita per day water consumption. It was very important to compare the calculated real consumption from each villa with the local regulations and the Vision 2030, in order to identify any deviation from the recommended municipal water consumption limit. The recommended water consumption guidelines in the Abu Dhabi, according to the Vision 2030, are shown in Table 2. According to the RSB (2009), the estimated water consumption for design purposes are shown in Table 3 .

The water consumption data from every villa were statistically analysed using the Minitab version - 17 statistical software. The statistical distributions (normal, log-normal, Gamma, etc.) of monthly water consumptions were conducted and the correlation and linear regression tests were conducted between the water consumption and family size. Different statistical parameters such as mean, median, minimum, maximum, and standard deviation were estimated. The Minitab version-17 was also used to perform the statistical distributions of water consumption data.

Table 2. Recommended water consumption guidelines according to the Abu Dhabi Environment Vision $2030(\mathrm{EAD}, 2012)$

\begin{tabular}{|c|c|c|c|c|c|}
\hline Priority Area & Priority & Outcome & Measure & $\begin{array}{c}\text { Baseline } \\
2010\end{array}$ & $\begin{array}{c}\text { Threshold } \\
2030\end{array}$ \\
\hline \multirow{3}{*}{$\begin{array}{l}\text { PA 3: Efficient } \\
\text { management and } \\
\text { conservation of water } \\
\text { resources }\end{array}$} & \multirow{3}{*}{$\begin{array}{l}\text { P } 3.1 \text { Integrated } \\
\text { and efficient use of } \\
\text { water resources }\end{array}$} & $\begin{array}{l}\text { 3.1.1 Moderate average } \\
\text { domestic water } \\
\text { consumption }\end{array}$ & $\begin{array}{l}\text { Domestic water } \\
\text { consumption in lpcd }\end{array}$ & 586 & $<340$ \\
\hline & & $\begin{array}{l}\text { 3.1.2 Moderate average } \\
\text { daily domestic outdoor } \\
\text { water use in villas and } \\
\text { shabiyat }\end{array}$ & $\begin{array}{l}\text { Domestic outdoor water } \\
\text { consumption (villa and } \\
\text { shabiyat) in lpcd }\end{array}$ & 756 & $<340$ \\
\hline & & $\begin{array}{l}\text { 3.1.3 Maximum use of } \\
\text { recycled water for amenities } \\
\text { plantation }\end{array}$ & $\begin{array}{l}\text { \% of total water } \\
\text { consumed for amenities } \\
\text { plantation }\end{array}$ & $35 \%$ & $67 \%$ \\
\hline
\end{tabular}

Table 3. Water demand and sizing criteria in the Abu Dhabi region (RSB, 2009)

\begin{tabular}{|l|l|}
\hline Water consumption categories in Villa and Shabiat & $\begin{array}{l}\text { Estimates of daily consumption } \\
\text { rate (litre) }\end{array}$ \\
\hline Per capita consumption & 350 \\
\hline $\begin{array}{l}\text { General services consumption (internal gardening and cleaning, additional quantity can be } \\
\text { estimated at } 1 \text { to } 1.5 \text { gallon/m } / \text { day) }\end{array}$ & $1100 / 2000$ \\
\hline Per bedroom (a reduction factor may be applied for additional bedroom as per ADDC criteria) & 500 \\
\hline Pool $/ \mathrm{m}^{2}$ & 30 \\
\hline
\end{tabular}




\section{RESULTS AND DISCUSSION}

\subsection{Monthly and Seasonal Water Consumption Pattern}

In order to verify the field data collected from water meters, the AADC DMA water consumption data of the study area was obtained for the same period. It was found that the field data collected from villas were closely matched with the AADC DMA consumption record. The AADC DMA consumption exhibited approximately 5\% more than the accumulated water consumption from meter readings. This $5 \%$ additional supplied water is generally used for network flushing, fire demand and lines losses.

The monthly water consumption in the study area is shown in Figure 1. It shows that water consumption decreased by about $2 \%$ of total consumption in the winter season (November - February). The monthly water consumption as a $\%$ of total water use is also shown in Figure 1. The monthly water consumption varies between $7 \%$ to $9 \%$ of total water use in the study area.

The Figure 2 shows the distribution of monthly water consumption among different villas in the study area. A total of nine houses was emptied and have zero water consumption. From the Figure 2, it is clear that water consumption mostly varies between 200 to $1400 \mathrm{~m}^{3} /$ month. Extremely high water consumption is observed in three villas only (1400 to $1800 \mathrm{~m}^{3} / \mathrm{month}$ ) and only nine villas exhibit low water consumption (less than $200 \mathrm{~m}^{3} /$ month). The median water consumption of 800 to $1000 \mathrm{~m}^{3} / \mathrm{month}$ is observed in 19 villas.

The statistical moments of monthly water consumption in different villas are shown in the Table 4. It shows that significant variations are observed in monthly water consumptions in different villas. Higher standard deviation exhibits this variation. The minimum water consumptions were found approximately near to 100 $\mathrm{m}^{3}$ and maximum consumptions were approximately $2000 \mathrm{~m}^{3}$. A negatively skewed distribution is observed for the months of May to October (summer season).

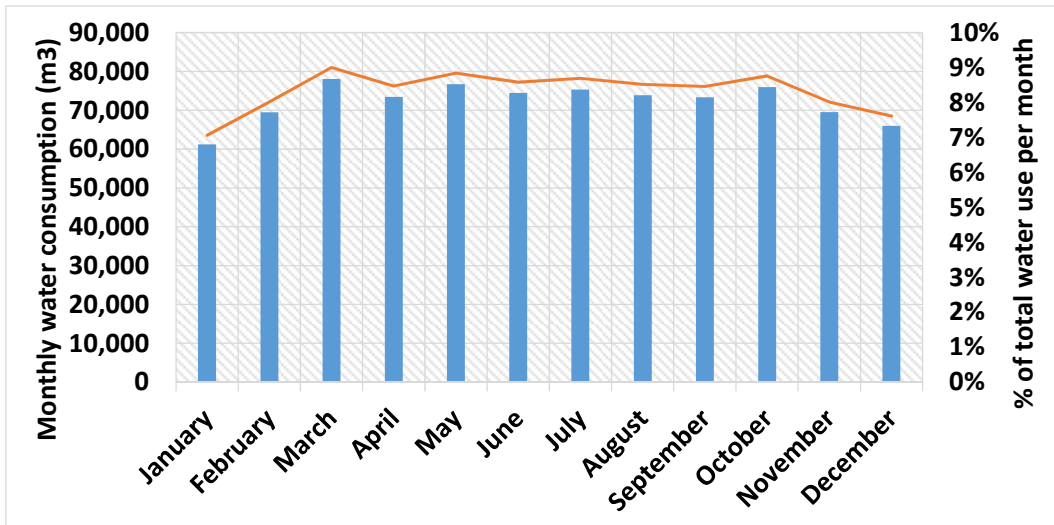

Figure 1. Monthly water consumption pattern in the study area (bar and solid line indicates water volume and $\%$ of total water use, respectively

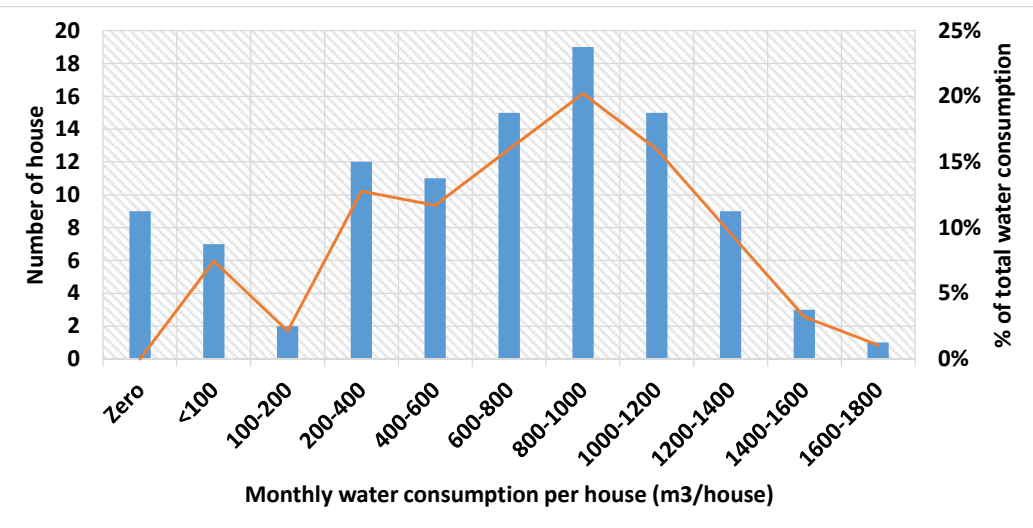

Figure 2. Water consumption pattern in villas (bar and solid line indicate number of villas and \% of total water consumption, respectively) 


\subsection{Per Capita Water Consumption}

Estimation of per capita per day water consumption is one the focal points in this study. Out of 100 villas, only the respondents from 35 villas were willing to participate in the questionnaire survey. Figure 3 shows the number of people in the villas and the per capita water consumption. The average, median and standard deviation of per capita water consumption for these 35 villas were found 3013, 2593 and 1971 lpcd, respectively.

It was observed from the surveyed 35 villas that the average number of people in the villas is 10 . Therefore, the total population in the study area (100 villas) was averaged by considering 10 people at every villa. After accumulation of overall consumption for a year, the average per capita per day water consumption was found equal to $2,577 \mathrm{lpcd}$ and the standard deviation of $613 \mathrm{lpcd}$. The average value is close to the actual average value obtained from the surveyed 35 villas. The value is significantly larger than the recommended value of the RSB regulation laws. The correlation between the number of people and the annual water consumption for 35 villas indicated that there is no

Table 4. Statistical characteristics of monthly water consumption in different villas

\begin{tabular}{|l|c|c|c|c|c|c|c|}
\hline Month & $\begin{array}{c}\text { Mean } \\
\left(\mathrm{m}^{3}\right)\end{array}$ & $\begin{array}{c}\text { Standard } \\
\text { Deviation } \\
\left(\mathrm{m}^{3}\right)\end{array}$ & $\begin{array}{c}\text { Minimum } \\
\left(\mathrm{m}^{3}\right)\end{array}$ & $\begin{array}{c}\text { Median } \\
\left(\mathrm{m}^{3}\right)\end{array}$ & $\begin{array}{c}\text { Maximum } \\
\left(\mathrm{m}^{3}\right)\end{array}$ & Skewness & Kurtosis \\
\hline February 2013 & 841 & 532 & 100 & 757 & 2,102 & 0.59 & -0.63 \\
\hline March & 897 & 495 & 102 & 858 & 2,017 & 0.30 & -0.75 \\
\hline April & 837 & 434 & 123 & 815 & 1,844 & 0.35 & -0.65 \\
\hline May & 845 & 399 & 122 & 859 & 1,753 & -0.06 & -0.78 \\
\hline June & 821 & 385 & 127 & 850 & 1,627 & -0.13 & -0.96 \\
\hline July & 833 & 363 & 135 & 848 & 1,637 & -0.13 & -0.72 \\
\hline August & 817 & 359 & 111 & 832 & 1,539 & -0.23 & -0.83 \\
\hline September & 810 & 368 & 127 & 859 & 1,621 & -0.21 & -0.87 \\
\hline October & 853 & 373 & 127 & 887 & 1,765 & -0.16 & -0.56 \\
\hline November & 803 & 399 & 109 & 814 & 1,796 & 0.10 & -0.52 \\
\hline December & 762 & 432 & 103 & 769 & 1,862 & 0.39 & -0.52 \\
\hline January 2014 & 731 & 474 & 103 & 639 & 1,992 & 0.62 & -0.59 \\
\hline
\end{tabular}
statistical significant correlation between them. This is particularly because a significant amount of water is used for outdoor activities, where a number of people has no influence.

\subsection{Indoor and Outdoor Water Consumption}

The sewer flow generated from the study area during the study period was obtained from the AADC (personal communication). The amount of water used for indoor activities was calculated as the difference of municipal water supplied to the area and the wastewater received at the sewer treatment plant. Table 5 shows the estimated wastewater generation (sewer flow) from the study area. It is evident that wastewater generation during June to November (summer season) is about $13 \%$ of total water consumed, whereas for other months the generation is $16 \%$. This clearly attributable to the more outdoor water uses, particularly for increased irrigation to plantations.

An estimation of $127,130 \mathrm{~m}^{3} /$ year of wastewater flow indicates that the indoor water consumption in the study area was $127,130 \mathrm{~m}^{3} /$ year $(15 \%$ of total water consumption) and the rest of $85 \% \quad(867,434-$ $127,130=740,304 \mathrm{~m}^{3} /$ year) was used for outdoor activities. Considering a total population of 994 (average family size of 10 per house) in the study area, it can be shown that indoor water consumption is about $350 \mathrm{lpcd}$ in the study area. The estimated outdoor water consumption rate is about $2040 \mathrm{lpcd}$.

The assessment results indicate that there was about $85 \%$ difference in the municipal water consumption and generated wastewater in the study area. This huge difference in quantity is generally due to the use of municipal water for outdoor activities such as irrigation to plantation and car washing.

Table 5. Estimated wastewater generation (in $\mathrm{m}^{3}$ ) from the study area

\begin{tabular}{|l|c|c|c|}
\hline Month & $\begin{array}{c}\text { Water } \\
\text { consumption } \\
\left(\mathrm{m}^{3}\right)\end{array}$ & $\begin{array}{c}\text { Generated } \\
\text { wastewater } \\
\left(\mathrm{m}^{3}\right)\end{array}$ & $\begin{array}{c}\text { Wastewater } \\
(\%)\end{array}$ \\
\hline January & 61,231 & 10,654 & 17 \\
\hline February & 69,473 & 10,878 & 16 \\
\hline March & 78,071 & 12,347 & 16 \\
\hline April & 73,429 & 12,558 & 17 \\
\hline May & 76,701 & 12,803 & 17 \\
\hline June & 74,433 & 10,059 & 14 \\
\hline July & 75,342 & 10,351 & 14 \\
\hline August & 73,916 & 9,461 & 13 \\
\hline September & 73,363 & 8,841 & 12 \\
\hline October & 75,964 & 9,635 & 13 \\
\hline November & 69,491 & 9,366 & 13 \\
\hline December & 66,020 & 10,177 & 15 \\
\hline Total & 867,434 & 127,130 & 15 \\
\hline
\end{tabular}




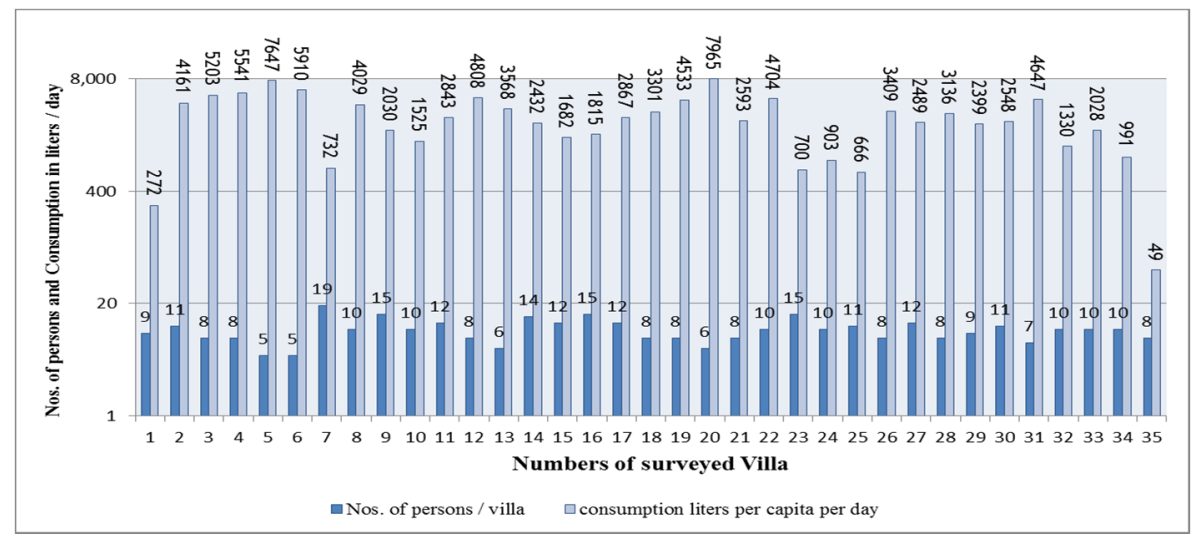

Figure 3. Number of people in 35 surveyed villas and their estimated per capita water consumption

\section{DISCUSSION AND CONCLUSIONS}

The estimated results demonstrate that the average water consumption in the medium sized villas in Abu Dhabi is more than 2,500 lpcd, which is about five times higher than the ADWEC and RSB estimated average consumption rate of $500 \mathrm{lpcd}$ in the region. The villas in the study area exhibit high water consumptions throughout the year and a slightly higher consumption is observed during summer months. The generation of wastewater was found less in the summer months - this indicates more water was used for outdoor activities. The consumption of water in villas were found independent of the number of people in the villas. Therefore, the most possible reason for high water consumption in the villas is outdoor water uses. The estimated indoor water consumption rate was found about $350 \mathrm{lpcd}$, which is reasonable. Therefore, in order to reduce the municipal water consumption (desalinated water) - the consumption in outdoor activities must be controlled. Alternative water sources such as the treated sewage effluent and treated greywater, both have the potential to reuse for outdoor uses (Chowdhury et al., 2014, 2015).

\section{ACKNOWLEDGMENTS}

The study was conducted with the financial support from the United Arab Emirates University - National Research Foundation (UAEU-NRF) Research Grant (Grant No. 31N135) awarded to the first author.

\section{REFERENCES}

Chowdhury, R.K., El-Shorbagy, W., Ghanma, M. and El-Ashkar, A. (2014). Quantitative assessment of residential water end uses and greywater generation in Al Ain city. Water Science and Technology: Water Supply, 15(1): 114-123.

Chowdhury, R.K., Sharvelle, S. and Beecham, S. (2015). Greywater quality changes in a permeable pavement reservoir. Water Management, DOI: 10.1680/wama.14.00107.

EAD (2008a). Terrestrial environment of Abu Dhabi Emirate - United Arab Emirates. Environment Agency - Abu Dhabi, UAE, ISBN \# ISBN978-9948-408-33-8.

EAD (2008b). Water resources of Abu Dhabi Emirate - United Arab Emirates. Environment Agency - Abu Dhabi, UAE.

EAD (2012). Advancing sustainable groundwater management in Abu Dhabi. Annual Policy Brief, Environment Agency - Abu Dhabi, UAE.

EAD (2014). Protecting our shared resources - sustainable water use for organization. Environment Agency - Abu Dhabi, UAE.

Friedler, E. and Hadari, M. (2006). Economic feasibility of on-site greywater reuse in multi-storey buildings. Desalination, 190: 221-234.

Nitivattananon, V. and Sa-nguanduan, N. (2013). Domestic water reuse situation in the context of middleincome countries: a case analysis. Frontiers in Environmental Engineering, 2(1): 7-17.

RSB (2009). Guide to Water Supply Regulation 2009. Regulation and Supervision Bureau, Abu Dhabi Emirate, UAE. 